\title{
Escrita e performance na poesia de autoria feminina contemporânea
}

Writing and performance in woman's contemporary poetry

Cinara Ferreira Pavani

Universidade Federal do Rio Grande do Sul

DOI: https://doi.org/10.5902/2176148537751

Resumo: A poesia de autoria feminina produzida a partir da segunda metade do século XX no Brasil destaca-se por seu caráter performático, na medida em que propõe a encenação do feminino e seu universo íntimo, assim como a dramatização de problemas relacionados às políticas de gênero. Levando em consideração estudos sobre escrita e performance, em especial de Roland Barthes e Graciela Ravetti, propõe-se a análise da poesia de autoras contemporâneas, com vistas a examinar sua performatividade e a repercussão dessa característica nos debates atuais sobre gênero.

Palavras-chave: Poesia de mulheres. Performance. Escrita.

Abstract: Poetry of female authorship made since the second half of the 20th century in Brazil stands out for its performatic character, as it proposes the enactment of the feminine and its intimate universe, as well as the dramatization of the problems related to gender politics. Taking in consideration studies about writing and performance, especially those by Roland Barthes and Graciela Ravetti, the analysis of poetry of contemporary female authors is proposed, with the goal to examine its performativity and the repercussion of this characteristic on current debates about gender.

Keywords: Women's poetry. Performance. Writing. 
por afrontamento do desejo

insisto na maldade de escrever

Ana $C$.

A escrita pode ser pensada como performance na medida em que é palco de encenação do real, do cotidiano, do pessoal e, em especial, daquilo que é da ordem do desejo. 0 entendimento da escrita literária como ato performático implica sua compreensão para além do signo. Mais que

Cinara

Ferreira

Pavani

104 portadora de sentidos, a literatura é presença. Ao transportar a experiência para a ficção, o escritor assume um papel político e convida o leitor às suas próprias performances. De acordo com Alex Beigui, a performance da escrita estabelece um movimento de mise-en-abyme, lugar de reconhecimento e desconfiança dos espaços legítimos do pensamento totalizador (2011, p. 35). Nessa perspectiva, a performance vem se mostrando como uma tendência crescente nas artes, contribuindo para trazer à cena questões identitárias fundamentais para o debate social e político.

A poesia de mulheres escrita no Brasil a partir dos anos 1980 caracteriza-se pela dramatização do feminino e seu universo íntimo, problematizando questões pertinentes às discussões de gênero. Segundo Graciela Ravetti, a "sobredeterminação dos discursos" oficiais inibe a vida cultural e a criação literária de mulheres e de outros grupos marginalizados, mas os atos performativos conseguem "assinalar pontos de fuga do círculo oclusivo da imposição de identidades e, consequentemente, de comportamentos ${ }^{1}$. . Nessa perspectiva, este artigo propõe a leitura da poesia da carioca Ana Cristina César e da gaúcha Angélica Freitas, com vistas a examinar sua performatividade e a repercussão dessa característica nos debates atuais sobre gênero.

Em "Literatura e mulher: essa palavra de luxo", publicado pela primeira vez em 1979 no Almanaque, cadernos de literatura e ensaio, Ana Cristina Cesar observa o quanto a crítica literária voltada à Cecília Meireles e Henriqueta Lisboa aproxima o universo poético dessas poetas a um ideário tradicional do feminino. Segundo Ana Cristina, via-se na delicadeza e na nobreza dos poemas escritos por mulheres algo de feminino ou silenciava-se qualquer referência ao fato de que se tratava de texto de mulher, como se falar nisso fosse irrelevante ante a realida-

1 RAVETTI, Graciela. Narrativas performáticas. In: RAVETTI, G.; ARBEX, M. (Org.). Performance, exilio, fronteiras: errâncias territoriais e textuais. Belo Horizonte: Departamento de Letras Românicas, Faculdade de Letras UFMG/Poslit, 2002. p. 47-68. 
de maior da Poesia. Ana C. exemplifica essas posturas críticas, citando trechos do prefácio de Bastide a um livro de Cecília Meireles: "Cecília levita, como um puro espírito... Por isso ela se move, 'viaja', sonha com navios, com nuvens, com coisas errantes e etéreas, móveis e espectrais, transformando em pura poesia essa caminhada" (1999, p. 26).

Reconhecendo que autoras 'elevadas' como Cecília Meireles e Henriqueta Lisboa abriram alas para a poesia de mulheres no Brasil e, por isso, ditaram o seu tom, Ana $\mathrm{C}$. pontua seu artigo de questões importantes até hoje para pensar a poesia de autoria feminina. A poeta preocupa-se com a identificação da escrita feminina com um ideário conservador que reforça seu apagamento como sujeito, na forma de preconceito em relação aos temas de mulher ou a um tom contestatório e de reivindicação de direitos:

Escrita e performance na poesia de autoria feminina contemporânea

Não quero ficar panfletária, mas não lhe parece que há uma certa identidade entre esse universo de apreensão do literário e o ideário tradicional ligado à mulher? $\mathrm{O}$ conjunto de imagens e tons obviamente poéticos, femininos, portanto? Arrisco mais: não haveria por trás dessa concepção fluídica de poesia um sintomático calar de temas de mulher, ou de uma possível poesia moderna de mulher, violenta, briguenta, cafona, onipotente, sei lá? (1999, p. 25).

Enquanto a recepção crítica dos textos de Cecília Meireles e Henriqueta Lisboa enaltece as características elevadas de sua escrita, a de uma poeta como Gilka Machado, por exemplo, vai questionar se a vida pessoal da escritora se reflete ou não nos seus poemas de cunho erótico. Gilka Machado rompe com o esperado de uma mulher que escreve em seu tempo, provocando opiniões controversas que tendem ao biografismo. Em errata ao referido artigo, dois anos depois, Ana Cristina identifica os traços da nova produção poética feita por mulheres brasileiras naquele momento, chamando a atenção para o perigo de cair em polo oposto, no qual a inversão se constitui como bandeira, com tendência normativa de como a mulher deve escrever:

\footnotetext{
Um nova produção e um feminismo militante se dão as mãos, propondo-se a despoetizar, a desmontar o código marcado de feminino e do poético. Cecília e Henriqueta nada mais seriam do que exemplos típicos de uma velha e conhecida retração e recalque da posição da mulher. Mas as boas moças já não estão na ordem
} 
do dia. A militância desencava com fúria uma operação de reviravolta, uma dialética do conflito, uma errata diabólica. Onde se lia flor, luar, delicadeza e fluidez, leia-se secura, rispidez, violência sem papas na língua. Sobe à cena a moça livre de maus costumes, a prostituta, a lésbica, a masturbação, a trepada, o orgasmo, o palavrão, o protesto, a marginalidade. A operação toda me parece uma virada inócua da cara em direção à coroa, uma proeza militante de troca em que importam menos os poemas do que uma poética da nova "poesia de mulher" (1999, p. 29).

Ferreira

Pavani

106

Resguardado o papel fundamental da militância para as transformações sociais no tocante às desigualdades de gênero, a discussão da poeta carioca incita a pensar na seguinte questão: como produzir uma poesia que ao não corroborar os modelos tradicionais de conduta feminina não se configure como pura adequação a uma agenda? Como a literatura de mulheres pode se construir sem ser normativa? Parece que a escrita de Ana Cristina César e de autoras que a sucederam, como Angélica Freitas, é uma resposta a essa questão, na medida em que se configuram como palco onde o feminino é dramatizado e problematizado em sua diversidade, a partir da intimidade e do deslocamento operado por uma forma que presentifica o corpo. O sentido de deslocamento é tomado de Roland Barthes, para quem o deslocar-se pode pois querer dizer transportar-se para onde não se é esperado, ou ainda e mais radicalmente, abjurar o que se escreveu (mas não forçosamente o que se pensou) quando o poder gregário o utiliza e serviliza (2007, p. 26).

Em seus estudos sobre performance, Paul Zumthor destaca que o poético, para gerar seus efeitos, tem a fundamental necessidade da presença ativa de um corpo (2000, p. 41). No caso da literatura de mulheres, o corpo tem uma presença ainda mais fundamental se considerarmos o seu apagamento nos textos de autoria feminina. Nessa perspectiva, como afirma Heloísa Buarque de Hollanda, o texto performático é uma tendência que se fortalece em autoras e artistas da chamada quarta onda do feminismo, que se delineia a partir de 2013 e nas quais o corpo se torna plataforma de expressão e protesto de demandas de mulheres plurais, invertendo-se "o pessoal é político" da terceira onda para "o político é pessoal" na quarta. ${ }^{2}$

2 Na Aula Inaugural do PPG-Letras da UFRGS, do Semestre Letivo 2018/1, intitulada A onda explosiva dos novos feminismos, no dia 19 de março, às 14 horas, no Auditório do ILEA, Campus do Vale. 
Os textos de Ana César versam sobre um espaço íntimo (não necessariamente biográfico) articulado com um diálogo com a tradição e expresso por textos híbridos em que poesia e prosa não estão separadas. Cenas de abril ${ }^{3}$, seu primeiro livro, cujo título já aponta a teatralidade, é composto de textos em diferentes formatos e tons, caracterizados pela fragmentação. O primeiro poema dá a tônica do livro, assinalando a mobilidade dos textos que se seguirão:

\author{
recuperação da adolescência \\ é sempre mais difícil \\ ancorar um navio no espaço
}

O poema sugere que tão difícil quanto ancorar um navio no espaço é recuperar a adolescência. Enquanto encenação, o poema quer chamar a atenção para o jogo. Não quer ser interpretado. Nisso consiste a força da literatura de Ana Cristina César, usando uma expressão de Rolando Barthes, para quem o texto deve jogar com os signos, em vez de destruí-los, a fim de instituir no seio da linguagem servil uma verdadeira heteronímia das coisas (2007, p. 27-28). A autora deixa marcado seu intuito de desacomodar palavras e sentidos sancionados. 0 poema seguinte enumera em versos definições do campo da poética, rompendo com a noção do lírico do ponto de vista clássico:

\footnotetext{
primeira lição

Os gêneros de poesia são: lírico, satírico, didático, épico, ligeiro.

O gênero lírico compreende o lirismo.

Lirismo é a tradução de um sentimento subjetivo, sincero e pessoal. É a linguagem do coração, do amor.

O lirismo é assim denominado porque em outros tempos os versos sentimentais eram declamados ao som da lira.

O lirismo pode ser:

a) Elegíaco, quando trata de assuntos tristes, quase sempre a morte.

b) Bucólico, quando versa sobre assuntos campestres.

c) Erótico, quando versa sobre o amor.

o lirismo elegíaco compreende a elegia, a nênia, a endecha, o epitáfio e o epicédio.
}

3 In: CÉSAR, Ana Cristina. Poética. São Paulo: Companhia das Letras, 2013. 
Elegia é uma poesia que trata de assuntos tristes.

Nênia é uma poesia em homenagem a uma pessoa morta.

Era declamada junto à fogueira onde o cadáver era incinerado.

Endecha é uma poesia que revela as dores do coração.

Epitáfio é um pequeno verso gravado em pedras tumulares.

Epicédio é uma poesia onde o poeta relata vida de uma pessoa morta.

Cinara

Ferreira

Pavani

108

Mais próxima do que se entende por lírico na modernidade e na contemporaneidade, Ana Cristina César subverte o conteúdo do poema, ao trazer para a cena um discurso teórico sobre a lírica. Conforme pontua Hugo Friedrich,

a obscuridade da lírica moderna fascina o leitor, na mesma medida em que o desconcerta. A magia de sua palavra e seu sentido de mistério agem profundamente, embora a compreensão permaneça desorientada. (...). Esta junção de incompreensibilidade e de fascinação pode ser chamada de dissonância, pois gera uma tensão que tende mais à inquietude que à serenidade. A tensão dissonante é um objetivo das artes modernas em geral (1978, p. 15).

O poema de Ana C. questiona o lugar dos discursos. A quebra de expectativa em relação a um conteúdo 'poético' é recorrente em vários textos da escritora e pode responder à questão levantada sobre a vinculação da poesia feminina e um conteúdo e a um tom sentimental e elevado. Ao contrário da poesia diáfana identificada em suas precursoras, os poemas de Ana Cristina César versam sobre sua intimidade, seus desejos, sua escrita, adquirindo um caráter performático, tanto porque expõem elementos de possível biografia quanto pelo viés crítico em relação aos padrões esperados em termos de texto de autoria feminina.

Graciela Ravetti utiliza a expressão "escrita performática” para se referir a tipos específicos de textos escritos nos quais certos traços literários compartilham a natureza da performance, recorrendo à acepção desse termo, em sentido amplo, no âmbito cênico e no sentido político-social. Para a autora, os aspectos que ambas noções compartilham, tanto no que se refere à teatralização (de qualquer signo) e à agitação política implicam: a exposição radical do si-mesmo do sujeito enuncia- 
dor assim como do local da enunciação; a recuperação de comportamentos renunciados ou recalcados; a exibição de rituais íntimos, a encenação de situações de autobiografia; a representação das identidades como um trabalho de constante restauração, sempre inacabado, entre outros. No poema que segue, a presença de um cotidiano fragmentado e, portanto, inacabado, compõe a performance:

Escrita e

performance

"nestas circunstâncias o beija-flor vem sempre aos milhares" na poesia Este é o quarto Augusto. Avisou que vinha. Lavei os sovacos e os pezinhos. Preparei o chá. Caso ele me cheirasse... Ai que enjôo de autoria feminina me dá o açúcar do desejo (2013, p. 23).

A poeta usa um tom coloquial para falar de um encontro e da sensação de enjoo diante da possibilidade de uma aproximação sexual. Ao trazer à tona o mais íntimo (mesmo que seja inventado), Ana César coloca em movimento uma política do corpo, a partir da qual a mulher se mostra enquanto tal. Sua escrita faz emergir um ritual íntimo e performático. Cabe lembrar, entretanto, que sua escrita atua no limite entre a confissão e o fingimento. Em Crítica e tradução (1999), a poeta indica a impossibilidade de expressar o íntimo quando diz: "aqui é fingido, inventado, certo? Não são realmente fatos da minha vida. É uma construção" (CÉSAR, 1999, p. 259). A autora reconhece que a intimidade, por mais que se tente expressá-la pela literatura, sempre escapa. o que fica é construção.

Ainda em Cenas de abril, em texto que compõe um conjunto com mais dois textos em prosa, sob o título de "Arpejos", Ana Cristina traz para cena uma situação íntima em que um eu poético feminino fala sobre seu corpo e seus projetos:

Acordei com coceira no hímen. No bidê, com um espelhinho, examinei o local. Não surpreendi indícios de moléstia. Meus olhos leigos não percebem que um vermelho a mais tem um significado a mais. Passei pomada branca até que a pele, rugosa e murcha, ficasse brilhante. Murcharam os meus projetos de ir de bicicleta à ponta do Arpoador. O selim poderia reavivar a irritação. Em vez disso decidi dedicar-me à leitura (2013, p. 26). 
Em uma narrativa que remete ao diário íntimo, a autora encena no texto uma situação cotidiana do corpo feminino pouco frequente até então na literatura de autoria feminina, um gênero 'elevado' em que o corpo da mulher não figurava. Assim, além do aspecto teatral, coloca-se aqui uma questão política, de confronto com uma escrita feminina bem comportada, tanto no que se refere ao conteúdo, quando no que diz respeito à forma híbrida da obra. Nessa perspectiva, de acordo com Ravetti, a performance nasce como um híbrido, ou pela mistura de

Cinara

Ferreira

Pavani gêneros, de suportes, de conteúdos, ou porque, como todo o processo de hibridação, implica contaminação (contágio) entre todas as partes envolvidas e a consequente modificação dos agentes participantes. Por isso, as artes performáticas interferem na política e a política na arte. Conforme pontua Homi Bhabha, os termos do embate cultural são produzidos performativamente (1998, p. 20).

O caráter performático é bastante evidente em Um útero é do tamanho de um punho (2012), de Angélica Freitas, uma das autoras que sinaliza a virada da escrita feminina para a chamada quarta onda do feminismo, conforme Heloísa Buarque de Hollanda. ${ }^{4}$ Nessa obra, que equipara o útero a um punho, a poeta dramatiza, pelo uso da ironia, a mulher, seu corpo e seu(s) comportamento(s) regulados pelas expectativas sociais:

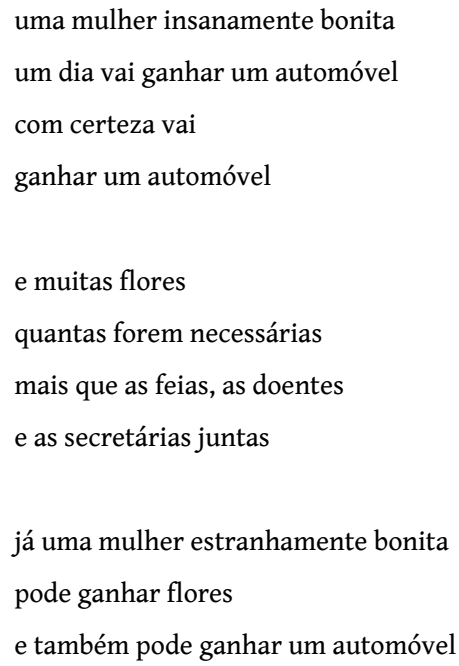

4 Na Aula Inaugural do PPG-Letras da UFRGS, do Semestre Letivo 2018/1, intitulada "A onda explosiva dos novos feminismos", no dia 19 de março, às 14 horas, no Auditório do ILEA, Campus do Vale. 
mas um dia vai

com certeza vai

precisar vendê-lo (2012, p. 18).

Angélica Freitas coloca em cena o estereótipo da mulher bonita a quem são oferecidos presentes por sua beleza. Quando a beleza é

Escrita e

performance na poesia de autoria feminina contemporânea

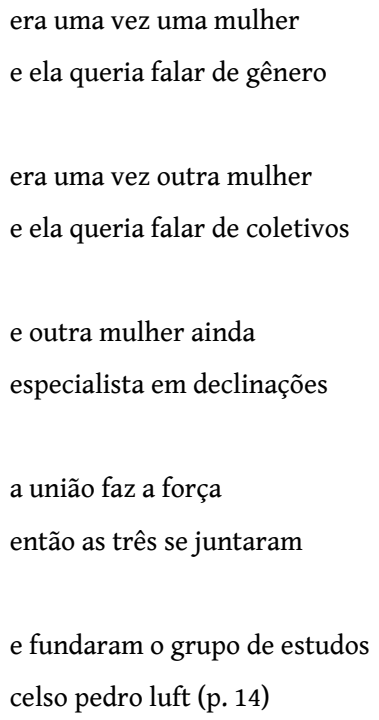

Do desejo de três mulheres nasce um grupo de estudos. 0 desejo é fundante da ação que rompe com o modelo feminino apresentado no poema anterior. Essas mulheres querem falar e, unidas, suas falas tornam-se performáticas no sentido político. Nesse sentido, é importante lembrar que, para Michel Foucault (2012), a representação discursiva e política definem com antecipação o critério que confere existência aos sujeitos mesmos e a esse critério pode-se chamar performativo. Também em Angélica Freitas, observa-se a pre- 
sença de uma escrita que encena o íntimo, afirmando a individualidade do sujeito representado em seu momento de dormir, em "eu durmo comigo":

Cinara

Ferreira

Pavani

112

eu durmo comigo/ deitada de bruços eu durmo comigo/virada pra direita eu durmo comigo/ eu durmo comigo abraçada comigo/ não há noite tão longa em que não durma comigo/ como um trovador agarrado ao alaúde eu durmo comigo/ eu durmo comigo debaixo da noite estrelada/ eu durmo comigo enquanto os outros fazem aniversário/ eu durmo comigo às vezes de óculos/ e mesmo no escuro sei que estou dormindo comigo/ e quem quiser dormir comigo vai ter que dormir ao lado (2012, p. 55).

Assim como Ana Cristina César traz o discurso teórico para o interior do poema, Angélica Freitas faz referência à definição da palavra "metonímia", figura de linguagem chave para entender o projeto do seu livro, que usa as imagens do útero e do punho para representar a mulher, seu corpo e seus embates:

\footnotetext{
alguém quer saber o que é metonímia abre uma página da wikipédia

depara com um trecho de borges em que a proa representa o navio

a parte pelo todo se chama sinédoque a parte pelo todo em minha vida este pedaço de tapeçaria é representativo? não é representativo?

eu não queria saber o que era metonímia, entrei na página errada eu queria saber como se chegava perguntei a um guarda não queria fazer uma leitura equivocada mas todas as leituras de poesia são equivocadas
} 


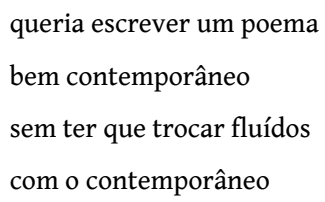

Angélica Freitas representa aqui o caminho da poesia. Ao confeminina trário de Ana César, que enforma o conceito de lírico no verso, ela não contemporânea quer definições prontas de uma enciclopédia anônima, mas quer saber como se chega "lá" e pergunta ao guarda. Sabe que todas as leituras de poesia são de antemão equivocadas. Admitindo o seu desejo de fazer um poema contemporâneo sem precisar se render a qualquer norma do que seja o contemporâneo, Angélica Freitas é barthesiana e, mais uma vez, performática. Para Barthes, a literatura encena a linguagem, em vez de, simplesmente, utilizá-la: "porque encena a linguagem (...), a literatura engrena o saber no rolamento da reflexividade infinita: através da escritura, o saber reflete incessantemente sobre o saber, segundo um discurso que não é mais epistemológico mas dramático" (2007, p. 19).

O caráter performático dos textos de Ana Cristina César e de Angélica Freitas constituem deslocamentos de uma norma em relação à escrita feminina atrelada a normas que associam o feminino ao doce, submisso, regrado e etéreo. Para Ravetti, a performance escrita funciona como um limite às elaborações ficcionais, como resposta aos mandatos identitários oficiais e é escutada/lida como convite a ir além do estipulado. A autora pergunta: que acontece quando os principais mandatos sociais são devolvidos à circulação - deformados, parodiados, desconstruídos, sofridos - e ficam convidativos para que os leitores realizem suas próprias performances? A escrita performática de Ana Cristina Cesar e de Angélica Freitas são convites para o questionamento e a transformação de práticas discursivas que legitimam a regulação da ação das mulheres. Como aponta Barthes, usando expressões de Mallarmé e Marx, "mudar a língua" é concomitante com "mudar o mundo" (2007, p. 23). 


\section{REFERÊNCIAS:}

BARTHES, Roland. Aula. 14. ed. Tradução de Leyla Perrone-Moisés. São Paulo: Cultrix, 2007.

BEIGUI, Alex. Performances da escrita. Aletria: Revista de Estudos de Literatura. v. 21, n. 1, jan./abr. 2011. p. 27-36.

Cinara CÉSAR, Ana Cristina. Poética. São Paulo: Companhia das Letras, 2013. Ferreira

Pavani CÉSAR, Ana Cristina. Literatura e mulher: essa palavra de luxo. Crítica e tradução. São Paulo: Editora Ática e Instituto Moreira $114 \quad$ Salles, 1999.

FOUCAULT, Michel. A arqueologia do saber. 8. ed. Tradução de Luis Felipe Baeta Neves. Rio de Janeiro: Forense Universitária, 2012.

FREITAS, Angélica. Um útero é do tamanho de um punho. São Paulo: Cosac Naify, 2012.

FRIEDRICH, Hugo. A estrutura da lírica moderna: da metade do século XIX a meados do século XX. Tradução de Marise M. Curioni. São Paulo: Duas Cidades, 1978.

RAVETTI, Graciela. Narrativas performáticas. In: RAVETTI, G.; ARBEX, M. (Org.). Performance, exílio, fronteiras: errâncias territoriais e textuais. Belo Horizonte: Departamento de Letras Românicas, Faculdade de Letras UFMG/Poslit, 2002. p. 47-68.

ZUMTHOR, Paul. Performance, recepção, leitura. Tradução de Jerusa Pires Ferreira e Suely Fenerich. São Paulo: EDUC, 2000. 